\title{
Understanding Customer Reactions to Brokered Ultimatums: Applying Negotiation and Justice Theory
}

\author{
Stephen E. Humphrey \\ Michigan State University \\ Donald E. Conlon \\ Michigan State University
}

\author{
Aleksander P. J. Ellis \\ University of Arizona \\ Catherine H. Tinsley \\ Georgetown University
}

\begin{abstract}
There has been little research examining customer reactions to brokered ultimatum game (BUG) contexts (i.e., exchanges in which 1 party offers an ultimatum price for a resource through an intermediary, and the ultimatum offer is accepted or rejected by the other party). In this study, the authors incorporated rational decision-making theory and justice theory to examine how customers' bids, recommendations, and repatronage behavior are affected by characteristics of BUG contexts (changing from an ultimatum to negotiation transaction, response timeliness, and offer acceptance or rejection). Results indicated that customers attempt to be economically efficient with their bidding behavior. However, negotiation structures, long waits for a response, and rejected bids create injustice perceptions (particularly informational and distributive injustice), negatively influencing customers' recommendations to others and their repatronage. The authors then discuss the practical and theoretical implications of their results.
\end{abstract}

Although negotiation has historically been viewed as a face-toface activity, many bargaining activities now take place between essentially anonymous parties. This has resulted in a concomitant increase in the reliance on intermediaries who facilitate interactions between buyers and sellers. For example, companies such as Expedia.com, Travelocity.com, and Orbitz.com serve as intermediaries between service providers (airlines, hotels, and car rental agencies) and the public. In addition, numerous discount intermediaries (such as Priceline and Hotwire) offer customers travelrelated items at prices that can be significantly lower than those offered through other intermediaries. In general, these contexts can be thought of as variations of ultimatum games (Güth, Schmittberger, \& Schwarze, 1982). Thompson (2001) defined ultimatums as situations in which

one person makes a final offer-an ultimatum-to another person. If the other person accepts the offer, then the first player receives the demand that he or she made, and the other player agrees to accept

Stephen E. Humphrey and Donald E. Conlon, Department of Management, Eli Broad Graduate School of Management, Michigan State University; Aleksander P. J. Ellis, Department of Management and Policy, University of Arizona; Catherine H. Tinsley, The McDonough School of Business, Georgetown University.

This research was supported in part by Grant N00014-96-1-0983 from the Cognitive and Neural Sciences Division of the Office of Naval Research. Support for this work is gratefully acknowledged, though the ideas expressed herein are those of the authors and are not necessarily endorsed by the funding agency.

Correspondence concerning this article should be addressed to Stephen E. Humphrey or Donald E. Conlon, Department of Management, N475 Business College Complex, Michigan State University, East Lansing, MI 48824-1122. E-mail: conlon@msu.edu what was offered to him or her. If the offer is refused, then no settlement is reached...." (p. 259)

The present study used the decision-making and justice literatures to develop and test hypotheses examining how people react to brokered electronic transactions. The literature on ultimatum games has primarily relied on theories of economic rationality in making predictions about behavior. We argue for taking a more comprehensive approach that uses both rational models of decision-making and organizational justice theory because we believe that the two approaches offer unique insights into different aspects of the ultimatum process. Figure 1 provides an overview of our study, including the variables we examined and the hypotheses that stem from each of the two theories we used to understand customer reactions. As can be seen in the figure, we used rational decision-making theory to investigate how the characteristics of the ultimatum context affect customers' current and future bidding behavior. We also used justice theory to investigate how procedural variations in an ultimatum context (ultimatum or negotiation transaction structure, timeliness of response, and intermediary response-offer acceptance or rejection) affect whether customers recommend the system to others, and whether customers would reuse (repatronize) the brokered ultimatum system. The dashed arrows in the figure indicate effects we expect to be mediated by participants' perceptions of justice.

Our study makes several contributions. First, we expand the theoretical scope of ultimatum bargaining situations by linking justice theory to structural characteristics of ultimatum games. Second, we explore the impact of changes in ultimatum bargaining structures and their effects on customer bidding behavior in present and future encounters. Third, we examine a heretofore unstudied negotiation context - brokered ultimatums - that broadens the generalizability of the ultimatum literature. Fourth, we use our results to argue for an expanded consideration of the fourfold 


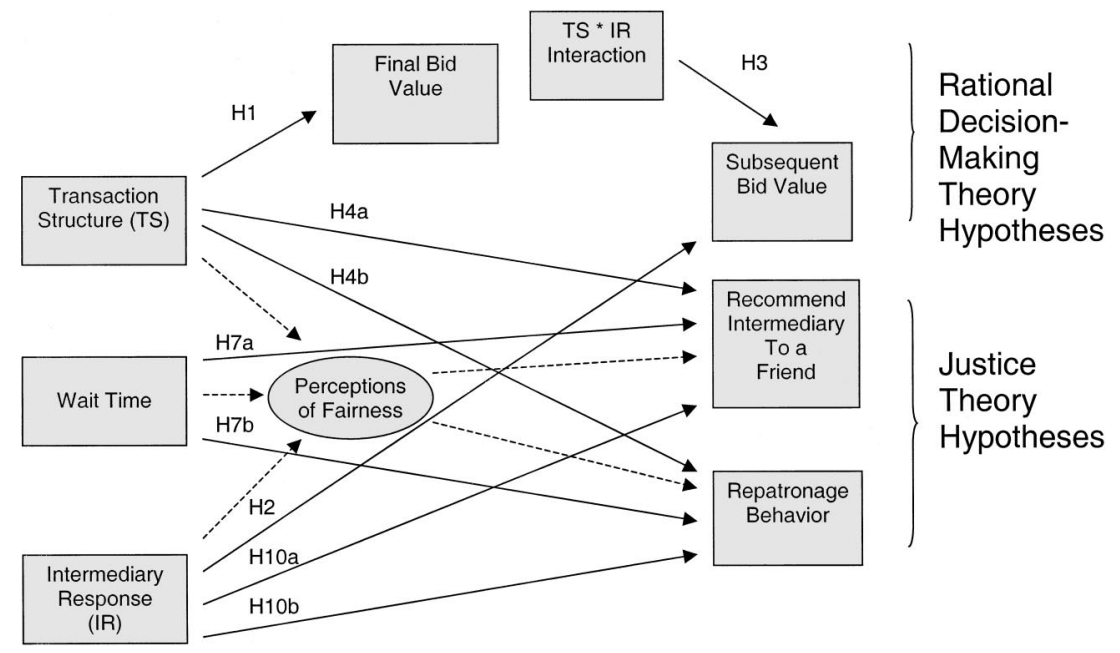

Figure 1. Overview of our study. Dashed arrows indicate our proposed mediational effects for fairness perceptions captured in H5-6, H8-9, and H11-12. "Final bid value" also serves as a control variable in predicting "subsequent bid values." $\mathrm{H}=$ Hypothesis.

model of organizational justice (cf. Colquitt, 2001) in understanding reactions to ultimatum situations. Fifth, we show how the decision-making and justice theories complement each other by predicting different types of reactions. Beyond these theoretical contributions, we also address the practical implications of our results for both customers and service providers who use brokered ultimatums. In the next section, we elaborate on the brokered ultimatum game (BUG) context. We then discuss the potential effects of certain structural characteristics of the BUG context on bidding behavior followed by their effects on customer recommendations and repatronage behavior. We conclude by discussing the practical and theoretical implications of our results as well as any limitations that stem from this research.

\section{The BUG Context}

Many discount travel bidding sites can be described as intermediaries that use an ultimatum structure to facilitate transactions between customers and vendors. Through the intermediary, vendors sell off their excess capacity to customers, allowing service providers an additional distribution channel at relatively low marginal costs. There are variations in how such services are structured. For instance, with Priceline the customer makes the bid for the resource (e.g., a hotel room), and the intermediary accepts or rejects their offer on behalf of a vendor. With Hotwire, the intermediary offers the price for the resource, and the customer accepts or rejects the offer. Conceptually, both are variations of the traditional ultimatum game, as the negotiation is not between the two parties who are actually providing the resources, but instead the transaction occurs between a representative of one of the resource providers (Fershtman \& Gneezy, 2001). We label this type of transaction a BUG, which we define as any exchange occurring through an intermediary in which an ultimatum price is offered for a resource by one party (either the customer or the service provider via the intermediary), and the ultimatum offer is accepted or rejected by the other party.
From the perspective of the intermediary, it is important to have a high percentage of successfully completed transactions, as the intermediary only makes money on completed exchanges. This goal is consistent with the goals of the customers and vendors, who also prefer completed transactions to noncompleted transactions. In addition, the intermediary also has an incentive to keep customers satisfied with the service provided to ensure that current customers will use the service again in the future (repatronage) and that they will make positive recommendations about the system to other people, thereby increasing the number of people who visit the intermediary and potentially increasing the number of transactions completed. These outcomes can be seen on the right side of Figure 1.

Given this alignment of customer and vendor interests and incentives, it would seem that online intermediaries are perfect channels for customers to access vendor services. However, another intermediary incentive runs counter to the customers' interests - the benefit the intermediary gets from selling its available assets at the highest possible price. It benefits the intermediary to sell its available assets at higher rather than lower prices for three reasons. First, if a customer overpays for an asset that the intermediary has for sale, the intermediary can keep the difference between what it paid its vendor for the asset and what the customer paid for it (cf. Elliott, 1999; eSmarts, 1998). Second, procuring higher prices may signal to vendors that customer traffic or demand is high at this intermediary, which may lead these vendors to do more business with the intermediary. Finally, the forwardthinking intermediary must also consider not only how the current exchange will affect a customer's current bid but also how the exchange will affect a customer's future bidding behavior.

\section{Effects of Structural Characteristics on Bidding Behavior}

The present study examined a brokered ultimatum structure in which the customer (i.e., an allocator) makes an offer for a service and the intermediary (i.e., the recipient) responds with an accep- 
tance or rejection of the offer. This structure is similar to what many people have experienced using a discount intermediary, and in at least one case is reflected in how intermediaries market themselves to customers (e.g., Priceline's slogan of "Name your own price"). However, the process in practice does not always conform to this model. For instance, some customers using Priceline are asked by Priceline to consider raising their bid prior to the bid being submitted for consideration. Of course, customers are free to ignore this suggestion and resend their initial bid or even submit a lower bid. ${ }^{1}$

Conceptually, asking customers to consider changing their offer effectively changes the transaction structure from an ultimatum situation to a negotiation situation (or from a no-haggle to a haggle negotiation). How will this affect customer bidding strategy? We expected that the prompt to consider changing the offer would lead to higher bids. The request comes as a surprise and violates customer expectations, because the customer is not told prior to using the intermediary that this might happen. Surprise has been characterized as a light distributive bargaining or contentious tactic that can be effective at flustering a party, with the end result being a concession to the other side (e.g., Pruitt, 1981). The intermediary also has more information than does the customer, and this information asymmetry may lead the customer to view him- or herself as having less power or expertise. In such cases, norms of acquiescing or accommodating to the more powerful or experienced party come into play (e.g., Cialdini, 1984). In our context, this would lead to concessions in the form of higher offers. Finally, the customer may trust in the knowledge and experience of the intermediary and thus follow the advice to raise his or her bid without reservation.

Hypothesis 1: Customers who experience a negotiation structure will make higher offers than customers who experience an ultimatum structure.

One can view customers who raise their bids as behaving consistently with rational decision-making theory, which examines the cognitive (rather than emotional or habit-based) dimensions of decision making (Dawes \& Kagan, 1988). In a rational decisionmaking process, one first defines a problem (such as getting a hotel room) and then identifies the criteria (or utilities) to be maximized (time and money saved, confidence that the good will be delivered, etc.) One then weighs the importance of these criteria, generates alternatives (here, potential bid amounts), rates each alternative on each criteria, and finally determines an optimal decision-meaning one that leads to the highest overall utility (Bazerman, 2002, pp. $3-4)$. We argue in Hypothesis 1 that if a customer receives a prompt to raise his or her bid and one interprets that prompt as supplying information increasing the chance that a bid will be accepted, then it may be rational for this customer to increase his or her bid.

If customers strive to be rational in their bidding behavior, we predicted that over time customers' bids would reflect their best estimation of how to maximize both bid acceptance and cost savings. This led us to predict that customers whose bids in the first transaction were accepted would be likely to offer a lower amount in a subsequent bid situation than will customers whose bids in the first transaction were rejected. Acceptance of the original bid may trigger a buyer's remorse (Bazerman, 2002;
Kagel \& Levin, 1986), in that customers may realize that any bid accepted by the intermediary was probably higher than was necessary to accrue the asset (Ball, Bazerman, \& Carroll, 1991). Because the intermediary will not accept the bid unless the bid is at or above the true value of the commodity, and only the intermediary knows the true value of the commodity, the successful buyer is likely to have overbid. Customers whose first bid was accepted have learned what a likely acceptable bid is and may now focus on maximizing cost savings, hence they will lower their bid the next time around.

Now consider situations in which offers in the first transaction are rejected. Customers who did not have their bids accepted are less likely to diagnose the information asymmetries in the bidding structure and are more likely to focus on maximizing the probability of their bids being accepted. Moreover, these customers have not learned what an acceptable offer amount is from the first transaction-they know only that their offer was insufficient. Thus, these customers are likely to raise their subsequent bids in an effort to achieve a successful transaction.

Hypothesis 2: Among those customers willing to reuse the intermediary, those whose offers are accepted in the first transaction will make lower subsequent bids for the same asset than those whose offers are rejected in the first transaction.

We also predicted an interaction between the intermediary's response in the first transaction and the structure of the first transaction (ultimatum or negotiation) on customers' bids in subsequent transactions. When customers' first bids are accepted in the ultimatum structure, they may experience a stronger belief that they overpaid for the commodity relative to the negotiation structure (in which they were prompted that their initial bid was too low). As noted by Bazerman (2002), when an initial offer is accepted without question (relative to when someone haggles back and forth), the buyer's remorse experience is strong. However, customers whose final bids are accepted in the negotiation structure are likely to assess that their initial bid was too low to be accepted. These parties should feel more utility or satisfaction that their bid was accepted (relative to those in the ultimatum condition) in part because they should perceive that their final bid was close to the true value or resistance point of the intermediary.

Thus, it is rational that customers who received accepted offers in the ultimatum condition experienced more remorse than those who received accepted offers in the negotiation condition. If this is the case, then in a subsequent negotiation, customers whose original bids were accepted in ultimatum structures are more likely to start with lower bids than will those whose bids were accepted in negotiation structures. However, customers whose bids were re-

\footnotetext{
${ }^{1}$ In fact, travel experts strongly encourage customers to ignore this prompt, as it is not only received by people who make very low bids (cf. Elliott, 1999). For example, at BiddingForTravel.com, the site administrator states: ". . .when bidding for an airline ticket, ignore the chart you may receive suggesting that your bid has a very low chance of being accepted and that if you raise your bid $\$ X X$, your chances will be increased to $\mathrm{X} \%$. In fact, I've seen where this suggested increase results in a fare higher than available fares purchased directly from the airline. Therefore, always ignore this message." (BiddingForTravel.com, 2002).
} 
jected in the first transaction would be likely to bid higher in a subsequent negotiation-regardless of the transaction structure, because they would not be experiencing any buyer's remorse (having failed to buy a room the first time). Moreover, they have less diagnostic information available to them, as they do not know how high a successful bid needs to be. Thus, we posit the following transaction structure by intermediary response interaction:

Hypothesis 3: For customers willing to reuse the intermediary, accepted offers from ultimatum structures will lead to lower subsequent bids than (a) rejected offers from ultimatum structures and (b) all offers from negotiation structures.

\section{Effects of Structural Characteristics on Customer Recommendations and Repatronage Behavior}

Although the decision-making perspective on negotiation provides insight on how customers will bid in brokered ultimatums, it does not address how such situations might influence other customer outcomes such as their willingness to use the system in the future (repatronage behavior) or the likelihood of recommending the intermediary to others. Enhancing customer repatronage and positive recommendations are critical for intermediary survival because these actions increase the traffic at the intermediary and provide more opportunities to create sales. Because it costs 5 times as much to attract a new customer as it does to retain an old customer (Desatnick, 1988), the importance of keeping current customers should not be underemphasized. Moreover, relaying positive experiences to others also benefits the intermediary. One study reported in Blodgett, Granbois, and Walters (1993) found that dissatisfied customers told an average of nine other people about their negative experience. Thus, it is also important to create conditions that lead customers to make positive comments to others.

Because the rational decision-making approach is derived from the economics literature, it is not surprising that its strength is in predicting economic outcomes (Stevenson, Busemeyer, \& Naylor, 1990). However, recent economics research has acknowledged that fairness theory is important in understanding decision making (Kagel \& Wolfe, 2001). Thus, we believe that customer fairness perceptions, as opposed to the rational decision-making perspective, will explain how characteristics of brokered ultimatums affect repatronage and recommendations. The current literature describes four forms of justice, each of which may play a role in explaining how characteristics of the intermediary-customer transaction affect customer outcomes. Distributive justice, or beliefs that the outcome one received was fair, derived from the work of Adams (1965), who argued that people were concerned not about the absolute level of outcomes per se, but whether those outcomes were fair. Procedural justice concerns the fairness of the formal processes used to make decisions (Thibaut \& Walker, 1975). Procedures should (a) be applied consistently across people and across time, (b) be free from bias, (c) ensure that accurate information is collected and used in making decisions, (d) have some mechanism to correct flawed or inaccurate decisions, (e) conform to personal and/or prevailing standards of ethics or morality, and (f) ensure that the opinions of various groups affected by the decision have been taken into account (Leventhal, 1980; Leventhal, Karuza, \& Fry, 1980). Interpersonal justice reflects the degree to which people are treated with politeness, dignity, and respect by those involved in executing procedures or determining outcomes. Finally, informational justice focuses on the fairness of the information provided as to why procedures were used in a certain way or why outcomes were distributed in a certain fashion (Bies \& Moag, 1986; Colquitt, 2001; Greenberg, 1993).

Fairness judgments have been meta-analytically linked to many organizational outcomes such as performance, job satisfaction, organizational commitment, and job withdrawal behaviors (Colquitt, Conlon, Wesson, Porter, \& Ng, 2001). Although some work has examined fairness in the context of ultimatum games (e.g., Pillutla \& Murnighan, 1995), this work has focused exclusively on distributive justice and has not explicitly considered other forms of justice. This focus on distributive justice likely arises because the ultimatum literature typically limits itself to situations involving monetary divisions (i.e., one party proposes a distribution of a sum of money, and the other party accepts or rejects the proposed division). Ultimatums involving the exchange of cash by one party for a nonfinancial resource by another party are not considered. Moreover, this work has generally focused on the justice perceptions of the recipient (cf. Handgraaf, van Dijk, Wilke, \& Vermunt, 2003). The literature has not examined how the recipient's decision to accept or reject an offer affects the offerer's justice perceptions. Additionally, this work has not examined intermediaries, the BUG paradigm, or the sorts of procedural variations that are the focus of this study. We applied a fairness perspective to how characteristics of brokered ultimatums affect customer outcomes (see Figure 1 for an overview) and developed our hypotheses below.

Changing the rules of the game. Although the prompt to customers to consider raising their offers should have a positive effect on the intermediary's short-term financial position in the form of higher bids (Hypothesis 1), we suspected that from a fairness perspective, there may be longer term problems with this strategy. We expect that the receipt of a suggestion to change their bid would lower customers' procedural justice judgments for several reasons. First, as customers were expecting an ultimatum structure and then endured a negotiation structure, this should strike customers as unethical and inappropriate, violating norms of ethicality. In addition, they may realize that they were being treated differently (a) relative to their own prior experiences or (b) relative to other customers, thereby violating a norm of consistency. Beliefs that the procedures are free of bias may also be reduced, as customers may intuit that the person suggesting the rebid is an interested party rather than a neutral party. Ethicality, consistency, and bias suppression are all elements of what make procedures fair (e.g., Colquitt et al., 2001; Leventhal et al., 1980).

The receipt of a suggestion may also have a negative effect on distributive justice judgments. Adams (1965) suggested that one way to determine whether an outcome was fair was to calculate the ratio of one's contributions or inputs to one's outcome, and then to compare that ratio with a comparison ratio. In our context, this might involve comparing how much you pay (your input) and what you receive (say, a hotel room) from the intermediary. In a negotiation structure, the ratio of customers' inputs (their bids) to outcome (potentially acquiring the asset) becomes less favorable when customers make a higher bid for the same outcome.

Regarding informational justice judgments, if customers in the negotiation condition are surprised by the suggestion to raise their 
bid, they are likely to view any explanation provided by the intermediary with some skepticism. Customers may view the explanation as simply an attempt to extract more money from them for the same resource. In this case, the negotiation condition should reduce informational justice judgments, as customers will likely view the explanation that accompanies the suggestion to raise the bid as lacking in accuracy, truthfulness, or sincerity. However, we expected the structure of the transaction to have no effect on interpersonal justice judgments. There was nothing in the request to raise the bid that is derogatory or impolite toward the customer, thus we did not expect this form of justice to be affected.

Turning to more distal reactions, we expected that if the negotiation structure led to declines in fairness judgments, then customers would be less willing to use the intermediary in the future. Meta-analytic data have demonstrated that distributive justice, procedural justice, and informational justice have moderately strong relationships to withdrawal behaviors (cf. Colquitt et al., 2001), which in our context would include decisions not to repatronize the intermediary. In the customer service literature, some prior research demonstrates that fairness judgments impact both customer repatronage decisions and recommendations. For example, in a scenario study describing a customer returning a product to a store, Blodgett, Hill, and Tax (1997) demonstrated that encounters high in distributive justice (e.g., because the complainant was offered a full refund rather than a $15 \%$ discount on a new purchase) and high in interactional justice (a construct reflecting elements of both informational and interpersonal justice) had a positive effect on customer repatronage intentions and on customer recommendations to others. Thus, we advanced two sets of hypotheses, the first positing direct effects of our manipulation on the customer outcomes and the second arguing that three specific forms of justice would mediate the relationships between the transaction structure and customer outcomes.

Hypothesis $4 a-b$ : Customers who experience a negotiation structure (a) will be less likely to recommend the system to others and (b) will exhibit lower levels of repatronage than will customers who experience an ultimatum structure.

Hypothesis $5 a-c$ : The effect of the transaction structure (ultimatum or negotiation) on customer recommendations will be mediated by (a) procedural, (b) distributive, and (c) informational justice judgments, such that justice judgments will be lower in negotiation structures, which in turn will decrease customer recommendations.

Hypothesis 6 a-c: The effect of the transaction structure (ultimatum or negotiation) on repatronage will be mediated by (a) procedural, (b) distributive, and (c) informational justice judgments, such that justice judgments will be lower in negotiation structures, which in turn will decrease repatronage.

The waiting game. Another interesting characteristic of BUGs surrounds how quickly they provide customers with a response as to whether their offer has been accepted or rejected. Because waiting occurs after the bid has been submitted, it cannot affect whether customers increase their current bids or not. However, it can certainly affect customer fairness perceptions and the distal outcomes of repatronage and recommendations. To the degree that long waits violate customer judgments of how the procedure should operate, dimensions of procedural justice, such as ethicality, consistency, and accuracy, are violated. Regarding informational justice, Conlon and Murray (1996) found that complainants who perceived that they had to wait a long time to get a reply from companies were less satisfied with the explanation the company provided. Beliefs that explanations are reasonable and that such information was communicated in a timely manner are central elements of informational justice (Colquitt, 2001). Finally, interpersonal justice judgments might also be influenced. A slow reply could convey symbolic information suggesting that the customer is not held in high respect or esteem. To the extent that delayed responses trigger feelings of disrespect, we expected interpersonal justice judgments to be reduced. We did not expect distributive justice judgments to be affected, however, as these perceptions focused on the fairness of the outcome per se rather than the wait associated with receipt of the outcome.

The customer service literature has documented that long waits for customer service lead to negative reactions in the form of reduced repatronage and negative word of mouth (e.g., Blodgett et al., 1997), though few studies have measured the mechanisms through which such outcomes occur. We argue that fairness perceptions are one such mechanism. Regarding repatronage and recommendation intentions, we note that fast replies signal responsiveness and attentiveness to the customer, thus delay should lead to less favorable reactions toward the intermediary. For instance, in a consumer complaint study, Conlon and Murray (1996) found that complainants who perceived that they had to wait a long time to get replies from companies reported being less likely to do future business with the company. Moreover, to the extent that transactions involving electronic intermediaries are known for their efficiency, having to wait violates users' expectations about the exchange, and as in our prior hypotheses should lead to less favorable recommendations, and less willingness to use the service in the future.

Hypothesis $7 a-b$ : Customers who endure longer waits to find out if their bids were accepted or rejected (a) will be less likely to recommend the system to others and (b) will exhibit lower levels of repatronage than will customers who endure shorter waits.

Hypothesis 8 a-c: The relationship between waiting time and customer recommendations will be mediated by (a) procedural, (b) interpersonal, and (c) informational justice judgments, as increases in waiting time will decrease each justice judgment, which in turn will decrease customer recommendations.

Hypothesis $9 a-c$ : The relationship between waiting time and repatronage decisions will be mediated by (a) procedural, (b) interpersonal, and (c) informational justice judgments, as increases in waiting time will decrease each justice judgment, which in turn will decrease repatronage.

Getting what you want. We expected that having one's bid accepted or rejected would have straightforward effects on customer outcomes. Again, because the acceptance or rejection comes 
after the bid has been submitted, it cannot affect the current bid, but rather it has implications for fairness perceptions and subsequent customer outcomes. In terms of fairness, having one's bid rejected has obvious implications for distributive justice. Fairness is often viewed with a self-serving lens (cf. Thompson \& Lowenstein, 1992), hence when people receive unfavorable outcomes, they are more likely to find these outcomes unfair. Moreover, receipt of unfavorable outcomes usually stimulates an extended consideration of why the negative outcome was received (Wong \& Weiner, 1981), which can lead people to question the fairness of the procedure as well as the source responsible for the outcome, such as a third party or an authority figure (cf. Colquitt et al., 2001; Lind \& Tyler, 1988). In our study, the intermediary was analogous to the authority figure because this was the entity that conveyed to the customer whether his or her bid was successful or unsuccessful. Meta-analytic reviews support this broad effect of outcomes on the four forms of justice. A meta-analysis by Cohen-Charash and Spector (2001) documented that outcome negativity has strong negative correlations with distributive and procedural justice judgments (other forms of justice were not examined); similarly, a meta-analysis by Colquitt et al. (2001) documented that outcome satisfaction was moderately correlated with all four forms of justice.

As noted in the introduction, customers should prefer completed transactions to non-completed transactions. The positive fairness judgments that stem from having one's bid accepted should lead to more favorable recommendations to others and more repatronage, relative to having one's bid rejected. For example, Blodgett et al. (1993) found that a global measure of perceived justice was positively related to repatronage intentions and negatively related to negative word-of-mouth behavior. Extrapolating from the metaanalytic studies of justice also provided support for these assertions. For example, if we view repatronage decisions as the obverse of job withdrawal decisions, we see that multiple forms of injustice lead to the decision to withdraw and not reuse the intermediary (cf. Colquitt et al., 2001).

Hypothesis $10 a-b$ : Customers whose offers are accepted (a) will be more likely to recommend the system to others and (b) will exhibit higher levels of repatronage than will customers whose offers are rejected.

Hypothesis $11 a-d$ : The effect of offer rejections or acceptances on customer recommendations will be mediated by (a) procedural, (b) distributive, (c) informational, and (d) interpersonal justice judgments, such that justice judgments will be higher when an offer is accepted, which in turn will increase customer recommendations.

Hypothesis $12 a-d$ : The effect of offer rejections or acceptances on repatronage will be mediated by (a) procedural, (b) distributive, (c) informational, and (d) interpersonal justice judgments, such that justice judgments will be higher when an offer is accepted, which in turn will increase customer repatronage.

Although we have posited that fairness judgments mediate the relationships between our manipulations and repatronage and recommendation decisions, we did not expect fairness variables to influence the value of subsequent bids, as fairness judgments would have already exerted their influence on the customer decision to use the system again or not. Subsequent bids are made only by those who made the decision to repatronize the intermediary. However, if we change perspective, we note that fairness judgments may affect the economic outcomes of the intermediary if such judgments lead fewer people to repatronize the system. Thus, although the decision-making literature and our interaction hypotheses posited that the lowest subsequent bids may stem from customers in ultimatum structures whose offers were accepted, the total revenue generated in this condition might be higher than many others if fairness judgments lead to a greater number of customers expressing a willingness to use the intermediary in the future.

To test our hypotheses, we conducted a laboratory experiment. This allowed for a controlled test of the impact of our structural manipulations as well as the ability to carefully measure organizational justice perceptions. It also allowed us to independently manipulate offer acceptance and rejection independent of the amount bid to more clearly investigate the effects of each factor while also being able to statistically control for bids in our analyses.

\section{Method}

\section{Participants, Research Design, and Procedure}

Business undergraduates $(N=154)$ at a large midwestern university participated in this study. The average age of the participants was 21.6 years, and approximately 53\% were men. All students were recruited from an upper-level business course and received course credit for their participation. A $2 \times 2 \times 2$ factorial design was used, varying transaction structure (ultimatum or negotiation), time waiting for a response (short or long), and outcome (offer accepted or rejected). Participants were randomly assigned to one of the eight conditions.

On arrival to the study, participants were informed that they would be helping to evaluate an on-line travel service similar to Priceline.com. They were further told that the travel service company (named PriceFine.com) was almost ready to begin using the service nationally but that they had hired the researchers to evaluate their system so they could better understand how customers make decisions about purchasing goods and services over the Internet. In addition, participants were told that in this phase of the study, the company was examining hotel bids that people make for rooms in different U.S. cities. Participants were then informed of their specific role in the evaluation. They were to make a bid on a hotel room for a trip to a vacation site (San Diego) with their significant other. Each participant was told that they had \$500 in spending money that was needed to cover their expenses in San Diego, including two nights at the hotel (traveling to San Diego was already paid for). It was indicated to the participants that all leftover money could be spent on incidental expenses during their trip.

After reading the instructions as to what they would be doing, the participants completed a short questionnaire. This questionnaire assessed their belief that they could perform the on-line bidding transaction (selfefficacy) and their history of using the Internet for purchases. After completing these scales, participants were informed that it was time to enter the bidding stage. Participants received printed computer screen pages that provided the actual normative information used by a real intermediary that indicated that the average retail price for a four-star hotel room in this area was between $\$ 189.00$ and $\$ 249.00$. Participants then wrote down their bid, which was taken by the experimenter to be entered into the expert system database to determine whether the intermediary would accept the bid. The experimenter then left with the completed bid form. 
The experimenter returned later with another printed computer screen that informed the participant whether his or her bid was accepted or rejected. All participants then completed a questionnaire that measured customer outcomes and their justice perceptions.

\section{Manipulations}

Transaction structure. In the negotiation condition, the experimenter returned shortly after the participants had made their initial offer with a sheet that had allegedly come from the expert system database. This sheet, modeled after one used by an actual intermediary, informed participants that their original bid had not yet been submitted because the system's analysis of the bid indicated that it had only a small chance of being accepted. The sheet suggested that participants consider increasing their initial bid. Participants were given a new sheet and they then wrote in their new bid (which could have been the same or a different bid). In the ultimatum condition, individuals were not interrupted and were not presented with the counterbid suggestion. They simply made their original bid, which was collected by the experimenter, who in this case did not reenter the room. As the negotiation-ultimatum conditions were randomly assigned to participants, it is important to note that the actual level of the initial bid was unrelated to whether the participant received the suggestion to change his or her bid.

Wait. Time spent waiting for an answer was manipulated by returning a decision to the participants either 4 or $15 \mathrm{~min}$ after they made the bid that was ultimately submitted to the intermediary.

Acceptance. After waiting the requisite amount of time, the experimenter returned to provide all participants with an answer regarding the bid they ultimately submitted to the expert system. Participants whose bids were accepted received a response that said, "Congratulations! Your offer price for a 4-star hotel room in San Diego was accepted. See your complete hotel itinerary and receipt for your trip below." Participants whose bids were rejected received a response that said, "Welcome back! We're sorry, but we could not find a hotel willing to accept your offer for a hotel room in the San Diego area." Again, this manipulation occurred independent of the amount of their final bid.

\section{Dependent Variables}

Justice. We measured procedural justice, interpersonal justice, informational justice, and distributive justice with adapted versions of the scales developed and validated by Colquitt (2001). Procedural justice was measured with six items that referenced the bidding procedures used by the intermediary $(\alpha=.70$; sample items included "Have the bid procedures used accurate information?" and "Have the bid procedures conformed to moral and ethical standards?"). Interpersonal justice was measured with four questions $(\alpha=.86$; sample items included "Has the intermediary treated you in a polite manner?" and "Has the intermediary treated you with respect?"). Informational justice was measured with five questions $(\alpha=.75$; sample items included "Has the intermediary explained the procedures thoroughly?" and "Has the intermediary communicated details in a timely manner?"). Finally, distributive justice was measured with five items that referenced the final decision made by the intermediary $(\alpha=.89$; sample items included "Is the final decision justified?" and "Does the final decision reflect the effort you put into the transaction?).

Positive recommendations. We assessed positive recommendations with two items adapted from prior research in the consumer complaint literature (Blodgett et al., 1993; Blodgett et al., 1997) and adapted to our context $(\alpha=.92$, items were "After this transaction, I would have no problem saying positive things about PriceFine.com to others" and "I would encourage friends and relatives to use PriceFine.com.").

Repatronage decisions and subsequent bidding behavior. After completing all other measures, participants were asked the following:

Imagine that you have just found out that you have a friend who will be getting married in San Diego in three months. You will be taking your significant other with you, so you need to get a four-star hotel room for the event."

Participants then answered two questions. The first question asked, "Would you use PriceFine.com again?" Participants chose either yes or no, which was our measure of repatronage. Participants were then asked to assume that they were willing to use PriceFine.com again and were asked to make a bid for a hotel in the same area of San Diego as they had earlier. Participants entered in the amount they were willing to bid in this second situation. Only those who indicated in the first question that they would use the intermediary again were used in the measure of subsequent bidding behavior reported below.

\section{Control Variables}

We also measured three variables to include as controls. We measured self-efficacy as it has been shown to impact motivation (Quiñones, 1995), and performance (Stajkovic \& Luthans, 1998). A 10-item scale $(\alpha=.81)$ adapted from Quiñones (1995) was used to measure participants' perceptions of their ability to perform the transaction successfully. For example, one of the items stated "I feel confident in my ability to get a hotel room using this bidding procedure." We also measured prior Priceline use as experienced bidders may use different strategies and react differently than those with less familiarity with these systems. This was measured with one item, which stated, "How many times have you used it [priceline.com]?" The response scale for this item ranged from $1=$ never to $5=$ more than three times. Finally, we controlled for gender, as studies of ultimatum bargaining have noted that women tend to make more generous offers than men (cf. Eckel \& Grossman, 2001; Murnighan \& Saxon, 1998). All participants were asked to report their gender. Gender was coded 0 for female and 1 for male.

\section{Results}

Although data were collected from 154 participants, 5 participants were excluded from analyses (3 participants did not complete any of the justice or outcome measures, 1 participant provided responses outside of the study parameters, and 1 participant did not provide gender), resulting in a final sample of 149 participants. The means, standard deviations, and intercorrelations for the variables of interest with these participants are presented in Table 1. Given the directional nature of all of the study's hypotheses, one-tailed significance tests were used in evaluating the significance of each of our hypothesized effects.

\section{Manipulation Checks}

We checked our manipulations with three questions at the end of the scenario. For the transaction structure manipulation, participants were asked, "Which of the following best describes the bid process you went through?" Participants circled either "I made one offer for a hotel room" or "I made an original offer, but the intermediary suggested I raise my offer, so I then made a second offer." The correct choice was circled by 73 of 77 respondents in the ultimatum condition and 65 of 68 in the negotiation condition, $\chi^{2}(1, N=145)=118.30, p<.001$. For the bid acceptance or rejection manipulation, participants were asked, "Did you get your hotel room?" and were told to circle either the yes or no response. The correct choice was circled by 72 of 73 participants whose offers were accepted, and by 71 of 72 respondents whose offers were rejected, $\chi^{2}(1, N=145)=137.11, p<.001$. Finally, for the wait manipulation, we asked the participants to indicate how long 
they waited, using a 5-point scale with response anchors of 2, 5, 10,15 , or $20 \mathrm{~min}$, respectively. We found that people in the 15-min wait condition $(M=3.13, S D=.87)$ felt that they waited longer than people in the 4-min wait condition $(M=1.96, S D=.62)$, $t(143)=9.36, p<.01, R^{2}=.38$.

\section{Tests of Hypotheses Related to Bidding Behavior}

Transaction structure and initial bid. Hypothesis 1 posited that individuals in the negotiation structure would make higher offers than those in the ultimatum structure. To test this hypothesis, we performed a hierarchical regression analysis where we regressed the final bid made by the participants (i.e., either the initial bid in the ultimatum condition or the second bid in the negotiation condition) on transaction structure. In this analysis, we first controlled for three variables that we felt could impact the results. We controlled for self-efficacy as it has been shown to impact motivation (Quiñones, 1995) and performance (Stajkovic \& Luthans, 1998). We also controlled for past experience with electronic intermediaries like Priceline, as experienced bidders may use different strategies and react differently than those with less familiarity with these systems. Finally, we controlled for gender, as studies of ultimatum bargaining have noted that women tend to make more generous offers than men (cf. Eckel \& Grossman, 2001; Murnighan \& Saxon, 1998). Collectively, these variables explained $6 \%$ of the variance in offers, with only the selfefficacy variable explaining a significant amount of variance $(B=$ $-.18, p<.05$, with higher self-efficacy leading to lower bids). We then entered the transaction structure manipulation on Step 2, which explained an additional $12 \%$ of the variance $(B=.35)$, $\Delta F(1,144)=21.72, p<.01$, with participants in the negotiation structure making significantly higher bids $(M=\$ 160.78)$ than those in the ultimatum structure $(M=\$ 133.04)$. Moreover, the initial bids made by those in the negotiation condition $(M=$ $\$ 129.18$ ) were not significantly different from those in the ultimatum condition, which also attests to the effectiveness of the manipulation. Thus, Hypothesis 1 was supported.

Transaction structure, bid acceptance, and subsequent bid. As mentioned earlier, we measured repatronage behavior by presenting participants at the end of the study with a second scenario that required them to return to the same city and acquire a hotel room of identical quality (four-star) as before. When asked if they would be willing to use the same intermediary to find a room, 103 of the 149 participants who answered said yes. For the 103 who said they would use the system again, we examined how our manipulations influenced their subsequent bid for this second hotel room. We performed a regression analysis similar to the one performed for bids in the first transaction. Results for subsequent bidding behavior appear in Table 2. On Step 1, we entered the control measures, which as a set did not explain a significant amount of variance, though we noted that higher self-efficacy led to lower subsequent bids. On Step 2, we entered the bids that were accepted or rejected in the first transaction. We entered these bids rather than the initial bids (which would be different only for those in the negotiation condition) because our logic for the interaction hypothesis focused on the bids that were accepted or rejected in the first transaction. These bids explained over $60 \%$ of the variance in subsequent bid values. On Step 3, we entered the experimental manipulations. In 
Table 2

Relationship Between Manipulations and Subsequent Bidding Behavior

\begin{tabular}{|c|c|c|c|c|}
\hline Step & Independent variable & $\beta$ & $\Delta R^{2}$ & $\Delta F$ \\
\hline \multirow[t]{3}{*}{1} & Gender & .07 & \multirow[t]{3}{*}{.04} & \multirow[t]{3}{*}{1.37} \\
\hline & Priceline use & -.04 & & \\
\hline & Self-efficacy & $-.18 *$ & & \\
\hline 2 & Final bid & $.83 * *$ & $.62 * *$ & 48.68 \\
\hline \multirow[t]{3}{*}{3} & Transaction structure & .02 & \multirow[t]{3}{*}{$.14 * *$} & \multirow[t]{3}{*}{29.12} \\
\hline & Wait & -.01 & & \\
\hline & Acceptance & $-.39 * *$ & & \\
\hline \multirow[t]{3}{*}{4} & Transaction $\times$ Acceptance & $.16^{*}$ & \multirow[t]{3}{*}{.01} & \multirow[t]{3}{*}{.55} \\
\hline & Wait $\times$ Acceptance & .00 & & \\
\hline & Transaction $\times$ Wait & -.05 & & \\
\hline \multirow[t]{2}{*}{5} & Transaction $\times$ Wait $\times$ & & & \\
\hline & Acceptance & $-.24 *$ & $.01 *$ & 1.90 \\
\hline Full-1 & statistics & & Total $R^{2}=.82$ & $F(11,90)=37.26^{* *}$ \\
\hline
\end{tabular}

Note. $\quad n=103$

$* p<.05 . \quad * * p<.01$.

Step 4, we entered the two-way interactions, and on Step 5, we entered the three-way interaction.

As predicted in Hypothesis 2, bid acceptance or rejection in the first transaction influenced the value of subsequent bids $(B=-.39$, $p<.01)$, with those whose original bids were accepted offering less in their subsequent bidding situation $(M=\$ 125.46)$ than those whose first bids were rejected $(M=\$ 156.10)$. However, of additional interest were the results in Steps 4 and 5. On Step 4, we found the hypothesized two-way interaction between transaction structure and whether prior bids were accepted or rejected $(B=$ $.16, p<.05)$. As predicted in Hypothesis 3 , the lowest subsequent bids came from customers whose prior offers were accepted in the ultimatum structure $(M=\$ 109.77)$. The average value of bids in this condition was significantly lower than those of participants in any of the other combinations in the two-way interaction $(M \mathrm{~s}=$ $\$ 146.58$ for the negotiation, accept condition, $\$ 151.92$ for the ultimatum, reject condition, and $\$ 161.67$ for the negotiation, reject condition), minimum $t(95)=4.10, p<.01$.

Table 2 also shows a significant three-way interaction $(B=$ $-.24, p<.05)$. The form of this interaction is presented in Figure 2. As can be seen in the figure, and consistent with the above two-way interaction, the lowest subsequent bids occurred in the ultimatum, short wait, acceptance condition and in the ultimatum, long wait, acceptance condition (\$106.59 and $\$ 112.78$, respectively). The highest bids $(\$ 165.00)$ in the subsequent transaction came from participants who experienced negotiation structures, long waits, and rejected offers in the first transaction. To summarize, in ultimatum structures, there were large (i.e., significant, using Tukey's honestly significant difference test) differences in the value of subsequent bids based on whether bids in the first transaction were rejected or accepted, independent of whether participants endured short or long waits. In contrast, in negotiation structures, waiting time and rejection mattered-long waits coupled with rejection led to higher subsequent bids than either short waits or long waits with acceptance.

\section{Tests of Hypotheses Related to Recommendations and Repatronage}

To test the hypotheses involving customer recommendations and repatronage, we performed a hierarchical ordinary least squares regression and a hierarchical logistic regression, respectively. Results appear in Table 3. For both analyses, we again entered our control variables first. Both gender and prior

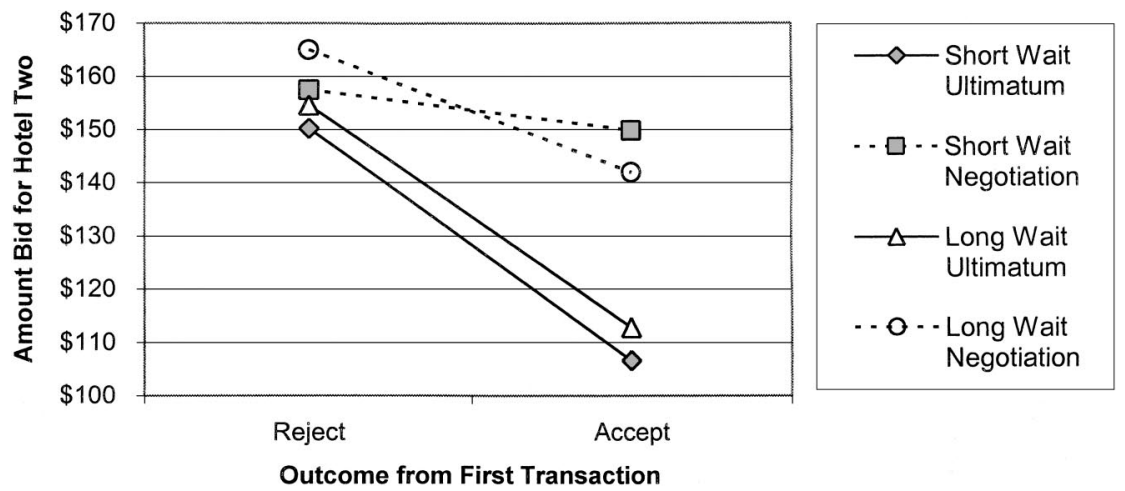

Figure 2. Three-way interaction between transaction structure, wait time, and offer acceptance on subsequent bidding behavior (includes only those who indicated they would use the intermediary again, $n=103$ ). 
Table 3

Relationship Between Manipulations and Customer Recommendations and Repatronage Behavior

\begin{tabular}{|c|c|c|c|c|c|c|c|}
\hline \multirow[b]{2}{*}{ Step } & \multirow[b]{2}{*}{ Independent variable } & \multicolumn{3}{|c|}{ Customer recommendations } & \multicolumn{3}{|c|}{ Repatronage behavior } \\
\hline & & $\beta$ & $\Delta R^{2}$ & $\Delta F$ & $B$ & Nagelkerke $\Delta R^{2}$ & $\Delta \chi^{2}$ \\
\hline \multirow[t]{3}{*}{1} & Gender & $.15^{*}$ & $.06^{*}$ & 2.95 & $.72 *$ & $.08 *$ & 8.59 \\
\hline & Priceline use & $.22 *$ & & & $.44 *$ & & \\
\hline & Self-efficacy & -.04 & & & .01 & & \\
\hline 2 & Bid & $-.18^{*}$ & $.03 *$ & 4.90 & -.01 & .02 & 2.27 \\
\hline \multirow[t]{3}{*}{3} & Transaction structure & $-.12 *$ & $.19^{* *}$ & 12.72 & $-.78^{*}$ & $.16^{* *}$ & 19.60 \\
\hline & Wait & $-.13^{*}$ & & & -.60 & & \\
\hline & Acceptance & $.42 * *$ & & & $1.57 * *$ & & \\
\hline \multirow[t]{3}{*}{4} & Transaction $\times$ Acceptance & .02 & .01 & .52 & -.60 & .01 & .84 \\
\hline & Wait $\times$ Acceptance & .10 & & & -.36 & & \\
\hline & Transaction $\times$ Wait & .12 & & & .51 & & \\
\hline \multirow[t]{2}{*}{5} & Transaction $\times$ Wait $\times$ & & & & & & \\
\hline & Acceptance & -.24 & .01 & 1.68 & $-2.91 *$ & $.01 *$ & 2.88 \\
\hline \multicolumn{2}{|c|}{ Full-model statistics } & & Total $R^{2}=.30$ & $F(11,137)=5.32 * *$ & & Total $R^{2}=.29$ & $\chi^{2}(11, N=137)=34.19 * *$ \\
\hline
\end{tabular}

$* p<.05 . \quad * * p<.01$.

Priceline.com use were significant, with men and those with more Priceline.com experience making more favorable recommendations and being more likely to reuse the intermediary. On Step 2, we entered the value of participants' initial bids as an additional control, which explained between $2 \%$ and $3 \%$ of the variance in each outcome. Hypotheses $4 \mathrm{a}-\mathrm{b}, 7 \mathrm{a}-\mathrm{b}$, and $10 \mathrm{a}-\mathrm{b}$ addressed the impact of transaction structure, waiting, and offer acceptance or rejection (respectively) on recommendations to others and repatronage behavior. We entered the manipulations testing these hypotheses in Step 3 of the regressions.

Tests of main effects. Hypothesis $4 \mathrm{a}-\mathrm{b}$ predicted that individuals in the negotiation structure would report less positive recommendations and exhibit less repatronage behavior. As can be seen in Table 3, the results of the regression analyses show that experiencing the negotiation structure has uniformly negative effects on our customer outcomes, as it decreases customer recommendations $(B=-.12, p<.05)$ and repatronage $(B=-.78, p<.05)$, with only 44 of 72 participants $(61 \%)$ in the negotiation condition agreeing to use the intermediary again, compared with 59 of 77 participants $(77 \%)$ in the ultimatum condition. Therefore, Hypotheses $4 \mathrm{a}-\mathrm{b}$ were both supported. Hypothesis $7 \mathrm{a}-\mathrm{b}$ predicted that longer waits for a response from the intermediary would lead to lower recommendations and less repatronage behavior. The data in Table 3 show that longer wait times did decrease customer recommendations $(B=-.13, p<.05)$, but did not have a significant effect on repatronage $(B=-.60, p<.10)$, with 48 of 74 participants $(65 \%)$ in the long wait condition agreeing to use the intermediary again, compared with 55 of 75 participants $(73 \%)$ in the short wait condition. Thus, the effect of waiting on recommendations (Hypothesis 7 a) was supported but the effect of waiting on repatronage (Hypothesis 7 b) was not supported. Hypothesis $10 \mathrm{a}-\mathrm{b}$ predicted that bid acceptance would increase recommendations and repatronage. As predicted, Table 3 demonstrates that having one's bid accepted leads to positive recommendations $(B=.42$, $p<.01)$, and repatronage $(B=1.57, p<.01)$, with 61 of 75 participants $(81 \%)$ whose bids were accepted agreeing to use the intermediary again, compared with only 42 of 74 (57\%) whose bids were rejected. Thus, Hypotheses $10 \mathrm{a}-\mathrm{b}$ were both supported.
Tests of mediation. Hypotheses $5 \mathrm{a}-\mathrm{c}, 6 \mathrm{a}-\mathrm{c}, 8 \mathrm{a}-\mathrm{c}, 9 \mathrm{a}-\mathrm{c}, 11$ $\mathrm{a}-\mathrm{d}$, and $12 \mathrm{a}-\mathrm{d}$ argued that the effects of our manipulations on customer recommendations and repatronage would be mediated by justice perceptions. As described in Baron and Kenny (1986), several steps are necessary to demonstrate mediation. In one step, the dependent variables are regressed on the independent variables. These results have already been described in Table 3. In another step, the mediators (in our case, the justice measures) are regressed on the independent variables. These results can be found in Table 4. As can be seen in Table 4, beginning with Step 1, we noted that our controls explained a significant amount of variance in procedural, interpersonal, and informational justice. For these three forms of justice, previous Priceline.com use led to more favorable fairness judgments. In addition, higher self-efficacy was associated with greater interpersonal justice. Entering the amount of customer bids on Step 2 did not explain a significant amount of variance for any justice measure.

On Step 3, we entered the experimental manipulations, which as a set explained a significant amount of variance (between $5 \%$ and $34 \%$ ) in each justice measure. We expected that the transaction structure manipulation would influence three forms of justice (procedural, distributive, and informational). However, the results show that only 2 of the 3 fairness judgments were affected. As expected, informational $(B=-.17, p<.05)$ and distributive justice $(B=-.16, p<.01)$ both decreased when parties were in the negotiation condition relative to the ultimatum condition. For the wait manipulation, we expected longer waits to reduce three forms of justice (procedural, interpersonal, and informational). Here we saw complete support, as procedural $(B=-.16, p<.05)$, interpersonal $(B=-.14, p<.05)$, and informational justice $(B=-.28$, $p<.01)$ were each significantly decreased by more waiting. Finally, our expectation that bid acceptance or rejection would influence all four forms of justice was supported, with procedural $(B=.20, p<.01)$, interpersonal $(B=.18, p<.05)$, informational $(B=.20, p<.01)$, and distributive justice $(B=.57, p<.01)$ all enhanced when bids were accepted. Thus, we have considerable evidence linking our mediators to the experimental manipulations, as 9 of 10 specific predictions were supported, though the trans- 


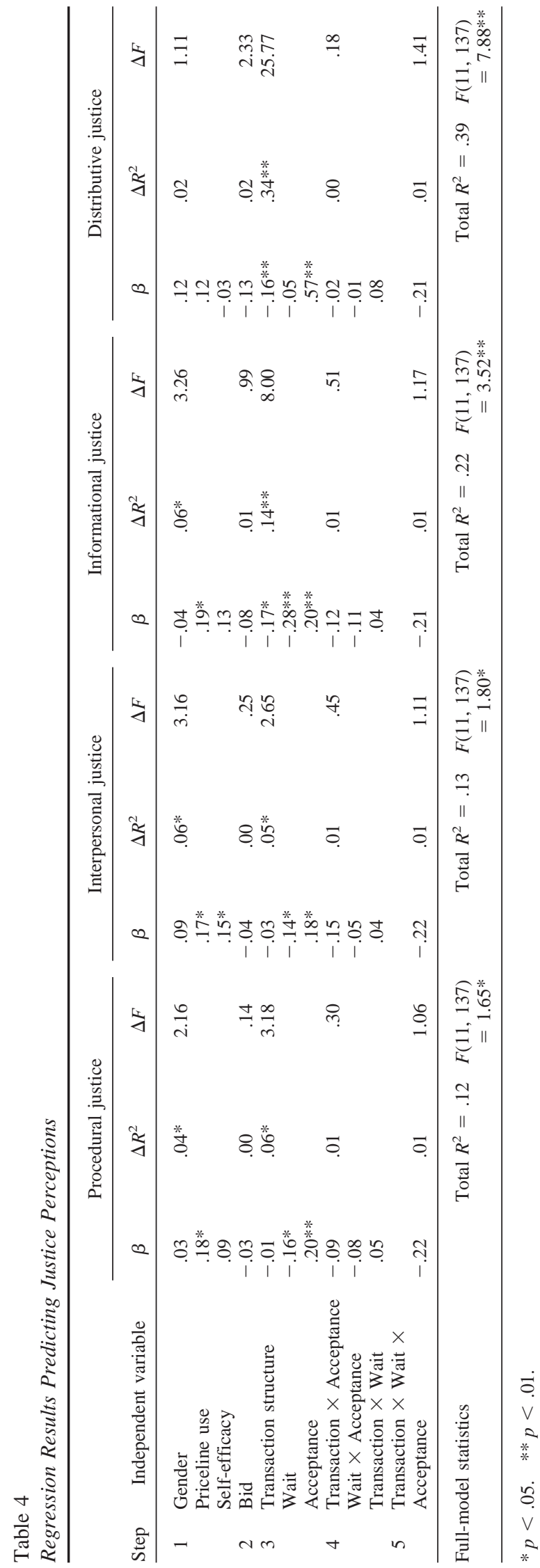

action structure and procedural justice relationship was not significant.

The final mediation step was to show that the direct effect of an independent variable on a dependent variable is reduced with the inclusion of the mediators. Specifically, this step captures whether the indirect path between the independent variable and the dependent variable is significant. There are alternative ways to capture this effect. Baron and Kenny (1986) recommended regressing both the mediator and the independent variable simultaneously and then comparing the beta coefficient of the independent variable in this equation with the beta coefficient from Step 1 of the mediation analysis. In addition, they recommended that researchers perform Sobel's test for the significance of the indirect path. However, using their method, only one path can be tested at a time, which in our study would both result in 36 analyses and would still neglect to capture the intercorrelation between the mediators.

A second option was to simultaneously test the direct and indirect paths with a path analysis. The benefits of a path analysis include provision of (a) standardized coefficients for both the direct and indirect paths between the independent and dependent variables, (b) coefficients that are directly comparable to the coefficients derived in regression, (c) significance tests associated with each coefficient, (d) maximum likelihood analyses, thus reducing concerns with dichotomous dependent variables (Nunnally \& Bernstein, 1994), and (e) a simultaneous analysis of all of the variables in the model, which allows for intercorrelation between the different mediators. In this study, this last benefit was critical as we have four justice mediators that were correlated. Specifically, as path analysis allows for simultaneous analysis, the total indirect path between one of our independent variables and an outcome captured the mediation effect of each justice variable and summed them into a coefficient that could be tested for significance. Thus, path analysis (through the $t$ test of the indirect effect) presented a test of the cumulative mediation of the justice variables.

Accordingly, we performed three path analyses in which we examined the direct and indirect paths between the three manipulations and the outcome of interest, using EQS version 5.7b (Bentler, 1995). Mediation can be inferred from the test if the indirect path is significant. Table 5 presents the direct, indirect, and total effects for each manipulation and each outcome. In addition, a $t$ test for each coefficient is presented next to that statistic. The last three columns present full-model fit statistics for the specific dependent variable. First, we present the chi-square to degrees-offreedom ratio, for which a ratio of 2.0 is used to indicate good fit (Arbuckle, 1997). Second, we present the comparative fit index (CFI), in which higher values indicate better fit and a value of .90 generally indicates good fit. Finally, we present the root-meansquare error of approximation (RMSEA), for which values below .05 indicate good fit and values between .05 and .08 indicate adequate fit.

As seen in the upper third of the table, for customer recommendations the indirect path for transaction structure $(B=-.10, p<$ $.05)$, wait $(B=-.08, p<.05)$, and bid acceptance $(B=.25, p<$ $.01)$ were all significant, demonstrating that justice mediated these relationships. This analysis also showed that bid acceptance was only partially mediated, as the direct path was still significant (i.e., the direct effect of bid acceptance on recommendations declined from .42 in Table 3 to .14 in Table 5). Regarding repatronage 
Table 5

Effects Decomposition for Mediation

\begin{tabular}{|c|c|c|c|c|c|c|c|c|}
\hline \multirow{2}{*}{$\begin{array}{l}\text { Independent } \\
\text { variable }\end{array}$} & \multirow{2}{*}{$\begin{array}{l}\text { Direct effect } \\
\text { (unmediated } \\
\text { effect) }\end{array}$} & \multirow{2}{*}{$\begin{array}{c}t \\
\text { (direct) }\end{array}$} & \multirow{2}{*}{$\begin{array}{l}\text { Indirect effect } \\
\text { (mediation by the } 4 \\
\text { justice measures) }\end{array}$} & \multirow{2}{*}{$\begin{array}{c}t \\
\text { (indirect) }\end{array}$} & \multirow{2}{*}{$\begin{array}{l}\text { Total } \\
\text { effect }\end{array}$} & \multicolumn{3}{|c|}{ Model statistics } \\
\hline & & & & & & $\chi^{2} / d f$ & CFI & RMSEA \\
\hline Recommendations & & & & & & 1.71 & .92 & .07 \\
\hline Transaction & & & & & & & & \\
\hline Structure & -.03 & -.57 & -.10 & $-2.08^{*}$ & -.13 & & & \\
\hline Wait & -.04 & -.62 & -.08 & $-1.71 *$ & -.12 & & & \\
\hline Acceptance & .14 & $2.03 *$ & .25 & $4.31 * *$ & .39 & & & \\
\hline Repatronage & & & & & & 1.71 & .91 & .07 \\
\hline Transaction & & & & & & & & \\
\hline Structure & -.08 & -1.05 & -.08 & $-2.16^{*}$ & -.15 & & & \\
\hline Wait & -.06 & -.88 & -.05 & -1.31 & -.11 & & & \\
\hline Acceptance & .07 & .88 & .21 & $3.76 * *$ & .29 & & & \\
\hline Subsequent bid & & & & & & 2.57 & .75 & .13 \\
\hline Transaction & & & & & & & & \\
\hline Structure & .35 & $4.38 * *$ & .02 & .79 & .37 & & & \\
\hline Wait & .09 & 1.03 & -.05 & -1.36 & .04 & & & \\
\hline Acceptance & -.20 & $-2.12 *$ & -.11 & $-1.85^{*}$ & -.30 & & & \\
\hline
\end{tabular}

Note. $\quad n=149$ for the customer recommendations and repatronage behavior measures; $n=103$ for subsequent bidding behavior, which only includes those willing to rebid. In all models, we controlled for gender, Priceline use, and self-efficacy. We controlled for bid in the recommendations and repatronage analyses, and controlled for final bid in the subsequent bid analysis. $d f$ for recommendations and repatronage $=141$; $d f$ for subsequent bid $=95 . \chi^{2} / d f$ is the ratio of the chi-square value to the degrees of freedom in the model. CFI $=$ comparative fit index. RMSEA = root-mean-square error of approximation.

$* p<.05$. $* * *<<.01$.

behavior, Table 5 shows that the indirect paths for transaction structure $(B=-.08, p<.05)$ and bid acceptance $(B=.21, p<$ $.01)$ were both significant, demonstrating mediation. The indirect path for wait $(B=-.05, n s)$ was nonsignificant.

Collectively, these results demonstrate that justice perceptions frequently, but not always, mediate the relationships between procedural differences and outcomes. Specifically, the data support Hypothesis $5 \mathrm{~b}-\mathrm{c}$ and Hypothesis $6 \mathrm{~b}-\mathrm{c}$, as distributive and informational justice were lower when the transaction structure switched to negotiation. Moreover, the indirect paths between transaction structure and (Hypothesis $5 \mathrm{~b}-\mathrm{c}$ ) customer recommendations and (Hypothesis $6 \mathrm{~b}-\mathrm{c}$ ) repatronage significantly decreased with the inclusion of these justice perceptions. The data also support Hypothesis $8 \mathrm{a}-\mathrm{c}$, as procedural, interpersonal, and informational justice judgments were lower when customers had a longer wait. Additionally, the indirect path between wait and customer recommendations significantly decreased with the inclusion of these three justice perceptions. However, Hypothesis $9 \mathrm{a}-\mathrm{c}$ was not supported, as wait was not significantly related to repatronage, rendering the test of this hypothesis moot. Finally, Hypothesis $11 \mathrm{a}-\mathrm{d}$ and Hypothesis $12 \mathrm{a}-\mathrm{d}$ received considerable support, as all four forms of justice were significantly higher when an offer was accepted. In addition, the indirect path between offer acceptance or rejection and (Hypothesis $5 \mathrm{~b}-\mathrm{c}$ ) customer recommendations and (Hypothesis $6 \mathrm{~b}-\mathrm{c}$ ) repatronage significantly decreased with the inclusion of the four justice perceptions, signifying mediation.

\section{Where Rational Decision Making and Justice Combine to Influence Bidding Outcomes}

For the sake of completeness, the bottom third of Table 5 also tests for whether justice judgments mediated the relationship be- tween our manipulations and the value of subsequent bids. Recall that we did not expect justice judgments to mediate the relationship between prior bid acceptance and the value of subsequent bids because justice judgments would have already exerted their influence on the customer decision to reuse the intermediary or not. Yet, as can be seen in Table 5, the justice perceptions did partially mediate the effects of prior bid acceptance on subsequent bid values, as one third of the total effect was attributable to the indirect path through the justice mediators, $t(95)=-1.85, p<.05$.

However, this analysis ignores the economic impact that occurs when customers decide not to repatronize the intermediary. An alternative way to evaluate subsequent bid values is to incorporate the effects of repatronage rates across experimental conditions. Evidence justifying this approach can be found in Table 3. Here, we see that in addition to the main effects for transaction structure and bid acceptance already discussed, there is a significant threeway interaction between transaction structure, waiting time, and bid acceptance on repatronage behavior $(B=-2.91, p<.05)$. Table 6 provides a breakdown across the eight experimental conditions of how subsequent bid values (the middle column) and the total economic value created (the last column) were affected when we did and did not incorporate customer decisions to repatronize. Although subsequent bid values were highest in the two negotiation, rejection conditions (the first two rows of Table 6), when we accounted for the number of people who chose not to rebid, the average value of bids in these two conditions (respectively) dropped from $\$ 165$ to $\$ 91.67$ and from $\$ 157.50$ to a meager $\$ 70.00$ - this last average value then became the lowest average value of any condition. Thus, fairness judgments do affect the overall size of the economic pie by impacting the number of people willing to reuse the intermediary, which suppresses the average value of subsequent bids. 
Table 6

Subsequent Bid Values and Repatronage Rates by Experimental Condition

\begin{tabular}{lcccc}
\hline \multicolumn{1}{c}{ Condition } & $\begin{array}{c}\text { Number of } \\
\text { customers } \\
\text { repatronizing }\end{array}$ & $\begin{array}{c}\text { Average value } \\
\text { of subsequent } \\
\text { bids (\$) }\end{array}$ & $\begin{array}{c}\text { Number of } \\
\text { customers not } \\
\text { repatronizing }\end{array}$ & $\begin{array}{c}\text { Average value of } \\
\text { subsequent bids (\$) } \\
\text { (including nonbidders) }\end{array}$ \\
\hline Negotiation, long wait, rejection & 10 & 165.00 & 8 & 91.67 \\
Negotiation, short wait, rejection & 8 & 157.50 & 10 & 70.00 \\
Ultimatum, long wait, rejection & 9 & 154.67 & 9 & 77.34 \\
Ultimatum, short wait, rejection & 15 & 150.27 & 5 & 112.70 \\
Negotiation, short wait, acceptance & 15 & 149.87 & 3 & 124.89 \\
Negotiation, long wait, acceptance & 11 & 142.09 & 7 & 86.83 \\
Ultimatum, long wait, acceptance & 18 & 112.78 & 2 & 101.50 \\
Ultimatum, short wait, acceptance & 17 & 106.59 & 2 & 95.37 \\
\hline
\end{tabular}

\section{Discussion}

We investigated the impact of three characteristics of BUG transactions on customer reactions. We confirmed that intermediaries could succeed in improving their short-term financial position (getting customers to raise their bids) by adopting a negotiation structure rather than an ultimatum structure. However, this strategy carries long-term costs. From a bidding perspective, we confirmed that those whose bids were accepted in the first transaction made lower bids in a subsequent transaction, especially when in an ultimatum (as opposed to negotiation) context. In terms of other customer outcomes, we see that characteristics of the bidding context (negotiation structures, long waits for a response, and rejected bids) produced feelings of injustice (particularly informational and distributive injustice), leading customers to feel less willing to recommend the system to others and less willing to use the intermediary in a subsequent negotiation (e.g., although over $90 \%$ of customers in the negotiation condition raised their bids in the first transaction, the repatronage levels for these same customers in the second transaction was only $61 \%$ ).

\section{Implications for Intermediaries and Their Customers}

Although the significant three-way interactions involving repatronage rates and subsequent bidding behavior each explain only $1 \%$ of the variance in behavior, they offer some insight into how intermediaries can manage rejections and requests to rebid. Using the last column of Table 6 as a guide, one sees that if you are going to reject bids, it is in fact best to do so using the promised structure (in this case, an ultimatum structure) and to provide feedback about bid acceptance or rejection quickly, as this results in the greatest proportion of "rejected" customers being willing to use the intermediary for a future transaction, leading to a high average bid value (\$112.70) in which nonbidders are included. The worst thing to do is to put a customer through the rigor of having to rebid and then turning around and quickly rejecting this new bid. This is the only condition in our study in which a majority of customers did not participate in the subsequent negotiation, reducing the value of subsequent bids from $\$ 157.50$ to $\$ 70.00$. This alternative view of subsequent bids also makes clear that surprising customers with a negotiation structure is not always bad-if you can be sure that you will then respond quickly to their offer with an acceptance, customers appear willing to use the intermediary again. This suggests that surprising customers with a request to raise their bids should be done only when the initial bids are already high enough to be accepted (and accepted quickly). Interestingly, this can explain why some real-world discount travel intermediaries ask parties to raise their bids even when the bid values are not unreasonably low. Perhaps they have already learned that doing so does not lead to negative reactions from customers as long as they accept these customer bids quickly.

Another answer to the question of how an intermediary might best manage to raise the value of subsequent bids and the number of subsequent participants might be found in our justice mediation results. Of the four forms of justice, the two that had the most widespread effects on customer outcomes were distributive and informational justice. Therefore, it seems reasonable to focus on actions that the intermediary might take to enhance distributive and informational justice as the mechanisms to leverage customer outcomes.

One way to enhance distributive justice is, of course, to give people more favorable outcomes. Then again, because enhancing distributive justice judgments for all participants in this manner would be expensive and might lead to the intermediary declaring bankruptcy, this may be impractical. However, recall from Adams's (1965) work that the formation of distributive justice judgments is based on a relative rather than an objective comparison. This suggests that companies might be able to enhance customer perceptions of distributive justice by providing them with normative data showing how many people who made similar bids were rejected.

This discussion on providing information to manage social comparisons leads nicely into our recommendations to enhance informational justice. First, we note that the procedural variation of the ultimatum versus the negotiation structure by itself communicates different amounts of information. Those in the negotiation structure have received more information as they are told that their offers have a low probability of being accepted. Although one might expect that the receipt of this additional information would enhance informational justice judgments, in reality it reduced informational justice judgments for those in the negotiation condition compared with the ultimatum condition. Our results make the interesting point that informational justice does not hinge on receiving more information but instead hinges on receiving good (or perhaps instrumental) information.

Second, we recommend that the intermediary provide all parties with an information-rich explanation about the transaction in 
which they are going to participate. Providing more details about what might happen and more information about why they received an acceptance or rejection should enhance informational justice judgments, and given the moderate correlations between all four forms of justice, may lead to other forms of justice being heightened. In addition, providing this information up front may also influence the attributions customers make for why they are asked to raise their bids. If more information leads more customers to perceive that the intermediary is acting altruistically rather than self-interestedly, this should lead to more positive short-term (value of bids) and long-term (repatronage) outcomes. Of course, doing this may make the electronic intermediary less desirable because it compromises how quickly parties can use the system, and people may have a limited attention span to read through multiple screens of information. Nevertheless, it may be helpful for the intermediary to provide more information to the most aggrieved parties - which could be defined either in psychological terms (by focusing on attitudes) or in behavioral terms (by focusing on repatronage rates and bidding behavior).

Turning our attention from intermediaries to customers, we note that our results suggest that individuals rely on both rational models of decision-making theory and fairness theory when interacting in brokered ultimatum contexts. When one focuses on the economic aspects of bidding, more cognitive decision analytic tools take precedence (though we note that fairness did partially mediate the effects of original bid acceptance or rejection on subsequent bid values). For example, when people's bids are rejected the first time around, they learn from this event, and the desire to complete a successful transaction leads these people to make higher subsequent bids than customers whose bids were accepted. This desire to win an acceptance the second time around appears to be exacerbated by having negotiated the first time. Having to negotiate creates additional costs for the customer (in terms of time and mental energy), so what customers may be trying to do in their subsequent bid is make up for the costs already incurred the first time (in which they put in time and energy and then walked away with nothing).

Although economists might argue that customers are irrationally thinking about sunk costs, psychologists might argue that customers who were rejected have learned that they need to increase their bids to get acceptance and that those who were rejected after putting in additional time and energy to rebid in a sense learned the hardest lesson and thus were the ones who increased their secondround bids the most. Of course, any customer following a learning model is not taking into account information asymmetries and intermediary advantages of this asymmetry. Customers should realize that what the intermediary is teaching them to do in a BUG context is to increase their bids. Prior research has demonstrated that taking the perspective of the other party can improve negotiator outcomes (cf. Bazerman, 2002). Customers would be wise to develop a broader learning model that incorporates the intermediary's perspective as well.

However, when customers are making broader assessments about whether to enter the brokered ultimatum context again or whether to recommend it to others, fairness judgments appear to be quite salient. Hence, we see that both decision-making and fairness perspectives are important for understanding the overall outcomes of customers and intermediaries over multiple exchange opportunities.

\section{Implications for Theory}

On the surface, our results appear to contradict those of a recent study by Galinsky, Seiden, Kim, and Medvec (2002), who found that parties were more satisfied with longer rather than shorter exchanges. In their study of a face-to-face negotiation, participants expected a negotiation situation that would take some time before an agreement was reached. When these expectations were violated, participants felt less satisfied. In our computer-mediated BUG context, participants expected an ultimatum situation to deliver a timely reply of an acceptance or rejection. When parties instead received a request to rebid or had to wait longer than they deemed necessary, violated expectations led to more negative customer reactions. Both studies make the same important point: Strive not to violate customer expectations. Together these results point out the critical role of context and participant expectations in understanding participants' reactions to various transactions. Decontextualized studies miss important environmental cues that form people's expectations about a transaction, and these expectations appear critical to attitudes and behavior. Hence, we echo recent calls for more socialized studies of how people transact an exchange (Bazerman, Curhan, Moore, \& Valley, 2000; Brodt \& Deitz, 1999; Tinsley, O’Connor, \& Sullivan, 2002).

Our results also make several contributions to the organizational justice literature. First, we used empirically validated scales that measured all four forms of organizational justice as articulated by Colquitt (2001) and others. In addition, this is one of the first studies to examine the impact of all four forms of justice within the same study, allowing us to compare the relative importance of the different forms of justice. Within our context, we see evidence for the importance of both distributive and informational justice on customer outcomes. However, although the receipt of more favorable outcomes enhances distributive justice, we see that informational justice is not necessarily enhanced by receiving more information (we also note that the negotiation structure, which provides more information to the customer, led to lower judgments of informational justice). In addition, our results highlight the surprisingly unimportant role played by procedural justice in our study. Interestingly, procedural justice was also not significant in some other work in the customer service literature that examined recommendations and repatronage (e.g., Blodgett et al., 1997) along with multiple forms of justice. It may be that informational and interpersonal justice constructs, when measured separately from procedural justice, usurp some of the prior relationships found in the literature between procedural justice and other outcomes.

We note that our justice variables did a better job of predicting customer recommendations than of predicting repatronage behavior. There are important differences between these two customer outcomes that might explain our results and offer opportunity for future research. First, customer recommendations are otherfocused whereas repatronage decisions are self-focused. Perhaps customers perceive unfairness to be something that is more important to other people than it is to themselves. Second, customer recommendations in this study were measured as behavioral intentions while repatronage was an actual behavior. Both metaanalytic and narrative reviews of the organizational justice literature have noted that justice measures have been more successful at predicting attitudinal variables than behavioral measures (e.g., 
Colquitt et al., 2001; Cropanzano, Rupp, Mohler, \& Schminke, 2001).

Finally, our results also confirmed our implicit theoretical proposition that rational decision theory, as a cognitive calculus, would be better at predicting the more detailed bidding calculations, whereas justice theory would be more useful in predicting more global reactions, such as whether to repatronize the system or recommend it to a friend. In our BUG context, we see the complementary nature of these theories and encourage future researchers to consider both the rational/cognitive and emotional/attitudinal drivers of behavior.

\section{Limitations}

As with any study, we must caution researchers on the generalizability of our findings. Our testing of hypotheses, using a controlled laboratory context and a simulation methodology, raises concerns that the participants were not able to achieve psychological realism (Berkowitz \& Donnerstein, 1982) during this study and that their results would not mimic results obtained from the field. However, we believe there are several reasons why this method for testing our hypotheses was appropriate.

First, testing our hypotheses in the laboratory setting allowed us to manipulate conditions in a way that would not be possible in the real world. For example, we were able to accept or reject the customer's offer regardless of the actual level of the bid. If we were to have tested these hypotheses in the field, the decision to accept or reject the bid would have been a function of the level of bid, thereby introducing a confound into the study (i.e., the customer's distributive justice perceptions would not be a function of getting the bid accepted, but rather the result of cognitive dissonance increasing justice perceptions and satisfaction because the customer bid a high amount of money). Second, among users of electronic intermediaries, significant percentages are of the same age and education level as our participants. Therefore, our participant population, if not completely representative of the users of electronic intermediaries, provided a comparable sample.

Third, there is a long history of capturing participants' economic and negotiation behaviors in laboratory settings (cf. Bazerman et al., 2000; Pruitt, 1998). In fact, this research has acted as the foundation of much of the economic and negotiation literature. In addition, research has demonstrated that the findings from laboratory studies are highly comparable to the results that are obtained from field settings (Anderson, Lindsay, \& Bushman, 1999). Thus, these issues mitigate some of our concerns about whether findings obtained from this laboratory context would differ from results obtained in a field setting. Finally, we recognize that this may be the first empirical test of a BUG. Although we feel that our setting was an appropriate first test of the BUG paradigm and of our theory predicting customer reactions, we also strongly encourage other researchers to expand the generalizability of our findings.

Our second concern relates to the materials used in our scenario. Participants did not complete their transactions electronically but instead received printed pages of computer screens. However, we did provide them with materials that closely replicated actual web pages in an attempt to mimic real-world settings. In addition, we can take some comfort in noting that prior work has demonstrated that electronic data collection is generally comparable to more traditional paper-and-pencil methods. Specifically, Stanton's
(1998) results indicated that electronic data had similar variance, factor structure, factor loadings, and correlations when compared with paper-and-pencil data using the same items and instruments. Another study (Birnbaum, 1999) compared an Internet sample with a laboratory sample and also produced similar conclusions for both samples. One obvious next step would be to make the bidding process a completely electronic transaction, rather than our more simplistic method, in an effort to further increase realism.

A third concern relates to the financial implications of our study for participants. Our participants were not using real money and may have been more willing to spend money and raise their bids than would people using real money to make similar decisions. We hope that we or other researchers can build ties with electronic intermediaries to obtain data on customer behaviors that are currently operating.

Another concern is that we had an unequal number of participants in each cell of the study, resulting in intercorrelations between our manipulations. As ordinary least squares regression is robust to different cell sizes (cf. Cohen \& Cohen, 1983), this does not affect the interpretation of our results. However, it increased the likelihood that individual differences were not equally distributed across the different conditions. This necessitated the use of control variables in our study to maintain the interpretability of our results, thereby reducing the overall power of our model.

Our fifth concern surrounds the potential of context effects on repatronage decisions. We acknowledge that the participants were given a different bidding context between the initial bid (i.e., a vacation with their significant other) and the subsequent bid (i.e., a wedding they would attend with their significant other). It is possible that participants perceived these two contexts as differing in urgency for obtaining a room, such that the participant may perceive that he or she needs to get the hotel room for the wedding. However, we are confident that the participants focused more on the fact that they were traveling to the same place and wanted to stay at the same caliber hotel with the same person rather than that one visit was for a vacation while another was for a wedding, as the information leading up to their decision emphasized these elements of the decision. Nevertheless, future research in this area should eliminate this potential alternative explanation by making the reason for the travel identical in both cases and by specifying that the participant has the same amount of money available for the purchase decision.

A final context-related concern deserves mention. Although we discuss Priceline.com in our introduction and our scenario paralleled some of the components found at Priceline.com, we were not actually testing how Priceline.com itself operates. Instead, our research examined how some of the aspects of intermediaries such as Priceline.com impact negotiation contexts. Thus, our research can aid in understanding the BUG context but was not intended to specify the dynamics of how a specific company or intermediary operates within this context. We think such contexts provide a variety of interesting theoretical questions to investigate, and the present study only begins to examine some of these questions.

Although we focused on one type of brokered ultimatum structure, there remain other intermediaries who use different structures to facilitate transactions between customers and vendors. Future research needs to investigate how customer behaviors and attitudes are affected in these types of contexts, as it is unclear whether organizational justice would play as significant a role when the 
customer is given more control over the system. Taken together, each of these steps will allow researchers to better understand and predict behavior within the BUG paradigm. It will also allow intermediaries to apply the gained knowledge in ways that may help sustain their survival over time.

\section{References}

Adams, J. S. (1965). Inequity in social exchange. In L. Berkowitz (Ed.), Advances in experimental social psychology (Vol. 2, pp. 267-299). New York: Academic Press.

Anderson, C., Lindsay, J. L., \& Bushman, J. (1999). Research in the psychological laboratory: Truth or triviality? Current Directions in Psychological Science, 8, 3-9.

Arbuckle, J. L. (1997). Amos users' guide (Version 3. 6). Chicago, IL: Small-Waters.

Ball, S. B., Bazerman, M. H., \& Carroll, J. S. (1991). An evaluation of learning in the bilateral winner's curse. Organizational Behavior and Human Decision Processes, 48, 1-22.

Baron, R. M., \& Kenny, D. A. (1986) The moderator-mediator variable distinction in social psychological research: Conceptual, strategic, and statistical considerations. Journal of Personality and Social Psychology, 51, 1173-1182.

Bazerman, M. H. (2002). Judgment in managerial decision making. New York: Wiley.

Bazerman, M. H., Curhan, J. R., Moore, D. A., \& Valley, K. L. (2000). Negotiation. Annual Review of Psychology, 51, 279-314.

Bentler, P. M. (1995). EQS structural equations program manual. Encino, CA: Multivariate Software.

Berkowitz, L., \& Donnerstein, E. (1982). External validity is more than skin deep: Some answers to criticisms of laboratory experiments. American Psychologist, 37, 245-257.

BiddingForTravel.com. (2002). Information from Priceline that should be ignored. Retrieved December 17, 2002, from http://pub109 .ezboard.com/fpricelineandexpediabiddingadministratorannouncements .showMessage?topicID $=138$.topic

Bies, R. J., \& Moag, J. F. (1986). Interactional justice: Communication criteria of fairness. In R. J. Lewicki, B. H. Sheppard, \& M. H. Bazerman (Eds.), Research on negotiations in organizations (Vol. 1, pp. 43-55). Greenwich, CT: JAI Press.

Birnbaum, M. H. (1999). Testing critical properties of decision making on the internet. Psychological Science, 10, 399-407.

Blodgett, J. G., Granbois, D. H., \& Walters, R. G. (1993). The effects of perceived justice on complainants' negative word-of-mouth behavior and repatronage intentions. Journal of Retailing, 69, 399-428.

Blodgett, J. G., Hill, D. J., \& Tax, S. S. (1997). The effects of distributive, procedural, and interactional justice on postcomplaint behavior. Journal of Retailing, 73, 185-210.

Brodt, S. E., \& Deitz, L. E. (1999). Shared information and information sharing: Understanding negotiation as collective construal. In R. Lewicki, R. Bies, \& B. Sheppard (Eds.), Research on negotiation in organizations (Vol.7, pp. 263-283). Greenwich, CT: JAI Press.

Cialdini, R. B. (1984). Influence: How and why people agree to things. New York: Morrow.

Cohen, J., \& Cohen, P. (1983). Applied multiple regression/correlation analysis for the behavioral sciences. Mahwah, NJ: Erlbaum.

Cohen-Charash, Y., \& Spector, P. E. (2001). The role of justice in organizations: A meta-analysis. Organizational Behavior and Human Decision Processes, 86, 278-321.

Colquitt, J. A. (2001). On the dimensionality of organizational justice: A construct validation of a measure. Journal of Applied Psychology, 86, $386-400$

Colquitt, J. A., Conlon, D. E., Wesson, M., Porter, C., \& Ng, K. Y. (2001).
Justice at the millennium: A meta-analytic review of 25 years of organizational justice research. Journal of Applied Psychology, 86, 425-445.

Conlon, D. E., \& Murray, N. M. (1996). Customer perceptions of corporate responses to product complaints: The role of explanations. Academy of Management Journal, 39, 1040-1056.

Cropanzano, R., Rupp, D. E., Mohler, C. J., \& Schminke, M. (2001). Three roads to organizational justice. In G. R. Ferris (Ed.), Research in personnel and human resources management (Vol. 20, pp. 1-113). Oxford, England: Elsevier Science.

Dawes, R. M., \& Kagan, J. (1988). Rational choice in an uncertain world. San Diego, CA: Harcourt Brace Jovanovich.

Desatnick, R. L. (1988). Managing to keep the customer. Boston, MA: Houghton Mifflin.

Eckel, C. C., \& Grossman, P. J. (2001). Chivalry and solidarity in ultimatum games. Economic Inquiry, 39, 171-188.

Elliott, C. (1999). Don't do their bidding: Travel auction sites prey on unsuspecting buyers. Retrieved December 17, 2002 from http:// abcnews.go.com/sections/travel/Crabby/crabby $990824 . h t m l$

eSmarts. (1998, July). Priceline: The real story. Retrieved December 17, 2002 from http://www.esmarts. com/priceline.html

Fershtman, C., \& Gneezy, U. (2001). Strategic delegation: An experiment. Rand Journal of Economics, 32, 352-368.

Galinsky, A. D., Seiden, V. L., Kim, P. H., \& Medvec, V. H. (2002). The dissatisfaction of having your first offer accepted: The role of counterfactual thinking in negotiations. Personality and Social Psychology Bulletin, 28, 271-283.

Greenberg, J. (1993). The social side of fairness: Interpersonal and informational classes of organizational justice. In R. Cropanzano (Ed.), Justice in the workplace: Approaching fairness in human resource management (pp. 79-103). Hillsdale, NJ: Erlbaum.

Güth, W., Schmittberger, R., \& Schwarze, B. (1982). An experimental analysis of ultimatum bargaining. Journal of Economic Behavior and Organization, 3, 367-388.

Handgraaf, M. J. J., van Dijk, E., Wilke, H. A. M., \& Vermunt, R. C. (2003). The salience of a recipient's alternatives: Inter- and intrapersonal comparison in ultimatum games. Organizational Behavior and Human Decision Processes, 90, 165-177

Kagel, J. H., \& Levin, D. (1986). The winner's curse and public information in common value auctions. American Economic Review, 76, 894920.

Kagel, J. H., \& Wolfe, K. W. (2001). Tests of fairness models based on equity considerations in a three-person ultimatum game. Experimental Economics, 4, 203-219.

Leventhal, G. S. (1980). What should be done with equity theory? New approaches to the study of fairness in social relationships. In K. Gergen, M. Greenberg, \& R. Willis (Eds.), Social exchange: Advances in theory and research (pp. 27-55). New York: Plenum Press.

Leventhal, G. S., Karuza, J., \& Fry, W. R. (1980). Beyond fairness: A theory of allocation preferences. In G. Mikula (Ed.), Justice and social interaction (pp. 167-218). New York: Springer-Verlag.

Lind, E. A., \& Tyler, T. R. (1988). The social psychology of procedural justice. New York: Plenum Press.

Murnighan, J. K., \& Saxon, M. S. (1998). Ultimatum bargaining by children and adults. Journal of Economic Psychology, 19, 415-445.

Nunnally, J. C., \& Bernstein, I. H. (1994). Psychometric theory. New York: McGraw-Hill.

Pillutla, M. M., \& Murnighan, J. K. (1995). Being fair or appearing fair: Strategic behavior in ultimatum bargaining. Academy of Management Journal, 38, 1408-1426.

Pruitt, D. G. (1981). Negotiation behavior. New York: Academic Press. Pruitt, D. G. (1998). Social conflict. In D. T. Gilbert, S. T. Fiske, \& G. Lindsey (Eds.), Handbook of social psychology (pp. 470-503). Boston: McGraw-Hill. 
Quiñones, M. A. (1995). Pretraining context effects: Training assignment as feedback. Journal of Applied Psychology, 80, 226-238.

Stajkovic, A. D., \& Luthans, F. (1998). Self-efficacy and work-related performance: A meta-analysis. Psychological Bulletin, 124, 240-261.

Stanton, J. M. (1998). An empirical assessment of data collection using the internet. Personnel Psychology, 51, 709-724.

Stevenson, M. K., Busemeyer, J. R., \& Naylor, J. C. (1990). Judgment and decision-making theory. In M. D. Dunnette \& L. M. Hough (Eds.), Handbook of industrial and organizational psychology (Vol. 1, pp. 283-374). Palo Alto, CA: Consulting Psychologists Press.

Thibaut, J., \& Walker, L. (1975). Procedural justice: A psychological analysis. Hillsdale, NJ: Erlbaum.

Thompson, L. L. (2001). The mind and heart of the negotiator (2nd ed.). Upper Saddle River, NJ: Prentice Hall.
Thompson, L. L., \& Lowenstein, G. (1992). Egocentric interpretations of fairness and negotiation. Organizational Behavior and Human Decision Processes, 51, 176-197.

Tinsley, C. H., O’Connor, K. M., \& Sullivan, B. (2002). Tough guys finish last: The perils of a distributive reputation. Organizational Behavior and Human Decision Processes, 88, 621-642.

Wong, P. T., \& Weiner, B. (1981). When people ask "why" questions, and the heuristics of attributional search. Journal of Personality and Social Psychology, 40, 650-663.

Received September 5, 2002 Revision received July 7, 2003 Accepted July 22, 2003

\section{Low Publication Prices for APA Members and Affiliates}

Keeping you up-to-date. All APA Fellows, Members, Associates, and Student Affiliates receive-as part of their annual dues-subscriptions to the American Psychologist and APA Monitor. High School Teacher and International Affiliates receive subscriptions to the APA Monitor, and they may subscribe to the American Psychologist at a significantly reduced rate. In addition, all Members and Student Affiliates are eligible for savings of up to $60 \%$ (plus a journal credit) on all other APA journals, as well as significant discounts on subscriptions from cooperating societies and publishers (e.g., the American Association for Counseling and Development, Academic Press, and Human Sciences Press).

Essential resources. APA members and affiliates receive special rates for purchases of APA books, including the Publication Manual of the American Psychological Association, and on dozens of new topical books each year.

Other benefits of membership. Membership in APA also provides eligibility for competitive insurance plans, continuing education programs, reduced APA convention fees, and specialty divisions.

More information. Write to American Psychological Association, Membership Services, 750 First Street, NE, Washington, DC 20002-4242. 